\title{
The Social Responsibility of the Private Sector and Its Role in Economic Development in the Kingdom of Saudi Arabia
}

\author{
Khamis Murayh Al Anazi Prof. Ismail Al Zyoud
}

\begin{abstract}
The study aimed to highlight the social responsibility of the private sector and its role in economic development in the Kingdom of Saudi Arabia, where the sample size reached 160, where the problem of the study was to explain the role of social responsibility for the private sector and its role in economic development in the Kingdom of Saudi Arabia, as the study concluded that there is a role for the sector The private sector in economic development in the Kingdom of Saudi Arabia, where it got 3.76\% with a high degree, and there are many obstacles that stand in the face of the private sector in social responsibility, which was at a high rate, where I got an average arithmetic (3.88). Study working on deepening and spreading the concept of social responsibility for the private sector in the Kingdom to provide a national project under which voluntary initiatives in the work and the development of civil society in the whole Kingdom and not limited to a specific area or provide food to the poor on a particular occasion without the direction to develop individuals, and work in accordance with comprehensive strategies based on Studies and research to find an executive mechanism for this partnership with the government sector, and the adoption of the private sector as a partner with the government sector in planning, implementation and evaluation.
\end{abstract} Keywords: social responsibility, private sector

DOI: $10.7176 / \mathrm{JEP} / 11-21-12$

Publication date:July $31^{\text {st }} 2020$

\section{Introduction}

Social responsibility emerged as a concept that establishes the idea of a corporate citizen. Saudi companies used to work in the private sector as a form of modern management practices, as social responsibility of the private sector was considered a cornerstone in the development of society, as it is extremely important in view of its importance in achieving globalization control and standing by the sector The government in reducing poverty and contributing to the development process (Al-Asraj, 2014), the relationship between sustainable development and corporate social responsibility in the Kingdom has received increasing attention recently, and those in charge of these companies are seeking to focus in their work on the rich in their society through specific strategies that support Charitable social and productive activities and activities in the country, with the aim of contributing to economic development on the one hand, earning customer loyalty and trust and maximizing profits on the other hand. Multiple studies indicate that social responsibility is a result of the requirements of sustainable development (and partnership in economic development between the state and the private sector to build a better future for future generations, by creating and supporting sustainable social, economic and cultural programs derived from national needs and priorities. Experts considered through these studies that This concept is based on investing in human resources, creating job opportunities, and providing a healthy and safe work environment along with solving social problems in the country by supporting businesses and projects that benefit the community and working to devote this concept with the aim of enhancing community solidarity and the satisfaction of its members in performing these activities Specialists also see that a large number of international companies that applied the concept of social responsibility in their practical environment, and their external activities have affected their profits and popularity positively, and increased public loyalty to them, which supported their economic competitiveness, and contributed to achieving sustainable economic development in the countries in which they operate attempts, through this specialized edition, to review the most prominent activities of companies and institutions in the Kingdom on The field of social responsibility, probing the concept and its positive returns on these companies and the local economy. Responsibility and society. new concepts Experts define the concept of social responsibility as an ongoing commitment by business companies to act ethically and contribute to economic development and work to improve the quality of living conditions for the workforce, their families, the community, and the community as a whole. The United Nations and the World Bank defined social responsibility as: "a voluntary commitment of private sector enterprises and working with their employees and society as a whole to improve people's livelihood in a manner that serves both commerce and society." This means that companies are obliged to provide programs to society while taking into account social and ethical considerations, while specialists indicate that community service programs in companies are not voluntary but rather a duty and an obligation dictated by belonging to the homeland, demanding that it be part of the community's culture and institutions to reach goals Desired. Experts also point out that the social responsibility of the private sector is everything that companies, whatever their size or field of work, voluntarily do in order to maximize their added value to society as a whole, and that it is the responsibility of every person in the company and not the responsibility of one administration, or one director, and it starts from Companies abide by different laws, especially those related to 
workers' rights and environmental protection, until they reach the development of society.

Businessmen consider that corporate social responsibility is a changing and evolving concept, organically linked to sustainable development. Companies, in addition to looking for profit, must pay attention to the environment and participate in economic and social development. According to the interested, it is: "The evaluation of private sector companies no longer depends solely on their profitability, and these companies no longer rely on building their reputation on their financial positions only, but modern concepts have emerged that help to create a work environment capable of dealing with the rapid developments in the economic, technological and administrative aspects Across the world, one of the most prominent of these concepts was the concept of corporate social responsibility. " Researchers confirmed, through a number of forums and conferences held in a number of global cities, that the role of the private sector is central to the development process, and that this was proven by the successes achieved by the advanced economies, after the private sector institutions realized that they are not isolated from society, and warned of the need to expand their activities To include more than productive activities, by giving adequate attention to society and the environment, and taking into account the three dimensions of sustainable development, namely economic growth, social progress and environmental protection. The researchers (Srivastava, 2018) pointed out that there is increasing evidence that CSR activities constitute a legitimate and convincing way to attract and retain employees, as well as attracting and retaining talent, as they pointed out that the most prominent international companies in this field are: " Home Depot, Delta Air Lines, and that there are a number of large and small companies, including Cisco Systems, General Electric and IBM, contribute to Encourage employees to participate in corporate social responsibility as a "strategic necessity". Good reputation and social activities The experiences of many countries, such as Germany and Japan, have shown that the most successful companies are those whose goals are not limited to profit-making.

The Kingdom of Saudi Arabia is considered one of the most prominent Arab countries that have taken care of the social responsibility of the private sector, as the private sector is an essential engine for economic growth in the Kingdom of Saudi Arabia, where the contribution of the private sector to the gross domestic product for the year 2012 at constant prices reached 57.6\%, and its growth rate reached $4.9 \%$ For the year 2012 at fixed prices.

Although it is difficult to implement social responsibility, as it is a new concept in the Kingdom, it has become extremely important because it is considered the cornerstone for achieving prosperity and stability in the long term in the Kingdom of Saudi Arabia, as the private sector occupies an important role in working to achieve economic and social development as well as achieving Development goals according to the vision of the Kingdom, due to the presence of capabilities and characteristics that qualify the private sector to influence in various economic and social areas, and this increases its importance and its role in economic activity in a way that pushes economic policy makers to focus on the mechanisms of its development and provide the appropriate climate for its activity Masoud, 2011) because The process of production in the private sector according to the market system and competition, and bear the risks as a result of the decisions taken, and the role of the private sector emerges as the main pillar for the establishment and development of economic activity in any country, as it is despite the existing controversy regarding the dimensions of its activity in light of the presence of the public sector, but the economic literature, despite Its differences indicate the great importance it plays in establishing a dynamic and prosperous economic activity, under the shadow of just now He fled a number of conditions that are considered the integrated framework for the private sector activity and activating its performance in the economic life. (Masoud, 2011).

\section{the importance of study :}

The importance of the study stems from two aspects:

1. Scientific importance: The scientific importance of this study is reflected in the attention of the local community to the importance of the role of the private sector in contributing to economic development in the Kingdom of Saudi Arabia, as the activation of social responsibility programs in the Kingdom of Saudi Arabia is considered one of the most important issues these days, especially in the context of the accident development At the local and international levels.

2. practical significance: reflects the practical significance of this study is that the importance of involving the civil sector to serve the members of the community local line with members of the requirements of society through economic development and thus contribute to the development of the Kingdom's economy, in addition to the desire of the government sector to find his partners in charge of performing many Social activities and services to raise the financial and administrative burden on him as this partnership helps to:

- Overcoming some chronic diseases that suffer from economic development in the Kingdom as a result of the increasing burdens placed on it, especially with the high rate of population growth.

Improve the efficiency of services provided to citizens.

- Strengthening accountability and participation and improving the response to the requirements of Saudi society.

\section{Study Problem :}

With the spread of the private sector in the Kingdom, the need arose to engage it alongside the state to achieve 
economic and social development plans that are characterized by a long-term strategic dimension, due to the availability of material resources for that in the private sector from the public sector, which helps in the economic development of the Kingdom and providing the needs of individuals and thus the preservation of the economy Nationalism in light of the current circumstances and the international struggle for the existence of globalization, interest in social responsibility of companies has increased in most Arab countries, and it has become a priority for the participation of the government sector in sustainable development. (Al Marwani, 2019). Economic development in the Kingdom of Saudi Arabia, by answering the following main question: What is the role of social responsibility for the private sector and its role in economic development in the Kingdom of Saudi Arabia?

\section{The main question is divided into several sub-questions:}

1- What are the positive effects of the participation of the private sector in the economic development of the Kingdom of Saudi Arabia?

2- What is the effect of spreading a culture of social responsibility for the private sector on the economic development of the Kingdom of Saudi Arabia?

3- What are the obstacles facing the private sector in the economic development of the Kingdom of Saudi Arabia?

\section{Study Objectives: This study focuses on the main objective:}

The role of social responsibility for the private sector in the economic development of the Kingdom of Saudi Arabia.

The main objective is divided into several sub-goals:

1. Identify the positive effects of the participation of the private sector in the economic development of the Kingdom of Saudi Arabia.

2. Knowing the impact of spreading a culture of social responsibility for the private sector on the economic development of the Kingdom of Saudi Arabia.

3. Knowing the obstacles facing the private sector in the economic development of the Kingdom of Saudi Arabia.

Theoretical framework of the study:

\section{First: The concept of social responsibility for the private sector.}

Increased interest in the issue of social responsibility for the private sector during the last three decades between researchers and politicians, as some researchers pointed out that business organizations are economic units that have a social role in their environments (Al-Qaryouti and others, 2014: 37), as the concept of social responsibility for the private sector came out of being practices Voluntary electives to compulsory practices that have become a source for achieving excellence, leadership and increasing competitiveness, to support the organization's survival and ensure its continuity, and that social responsibility can be a source of opportunities and innovation and enhance competitiveness (Rashi, 2014).

The concept of social responsibility for the private sector has developed significantly during the fifties, within the scientific literature, where this term appeared for the first time by Bowen in 1953, due to the continuous criticism of the concept of profits, so there were motives for companies to adopt a major role towards the environment in which they operate to become clear In recent decades (Nazzal, 2011).

The views that dealt with the concept of social responsibility differ, as he put forward many different definitions of the meaning of corporate social responsibility, as he defined it (kolter, 1991) is "a commitment to improve the welfare of society through discretionary business practices and contributions from company resources", where he used the term corporate social initiatives To describe great efforts under the corporate social responsibility umbrella that "corporate social initiatives are the company's primary activities in support of social issues and the achievement of corporate social responsibility" (kotler \& Lee, 2008: 3).

The Organization for Economic Cooperation and Development also defined social responsibility as: "the organization's commitment to contribute to economic development, while preserving the environment and working with workers and their families, the community, and society in general, with the aim of improving the quality of life for all of these parties."

As defined by (Al-Fadl and Ghadeer, 2012: 8), it is a set of decisions and actions taken by the organization to achieve the desired goals and prevailing values in society, which ultimately are part of the direct economic benefits of the management of the organization and seek to achieve it as part of its strategy.

\section{Second: The goals and benefits of corporate social responsibility}

The objectives of social responsibility in general are as follows:

- Demonstrate the ability to always provide the product, product or service, in accordance with customer requirements.

Increasing customer and employee satisfaction through effective system implementation.

Improve the capabilities and overall performance of the business to meet the needs and expectations of its clients 
and other stakeholders.

- Establishing and evaluating the effectiveness of the measures taken by the institution in order to introduce and comply with the policy and environmental and social goals.

Reducing and minimizing the risks that individuals can be exposed to in terms of safety and health, both at work and society, which reduces the number of lawsuits.

- Show the beneficiary groups that the Foundation's policies are compatible with the basic rights of work and society.

- Helping in developing a more effective dialogue with the beneficiary parties, with the help of the Foundation, to collect their various needs and aspirations to better manage and achieve a balance between social, economic and environmental performance (Saleh, 2015: 12).

Third: The theory used by the study:

The study is based on the theory of social responsibility that appeared in the United States of America, through the report published by the "Hutchins Committee" report in 1947 entitled "Responsible Free Press" which is the basis for the theory of social responsibility. This theory was developed under a number of interwoven social conditions Among them are: "The high rate of education, the increase in people's interests in public issues, and their increasing criticism of media practices. In addition, the economic system raised a number of problems where problems of balance and objectivity were raised as a result of the tendency of newspaper owners to express their political and economic views at the expense of opposing opinions, in addition to the increasing trend To monopoly and concentration in the ownership of the press, which led to the imposition of economic concepts and reduced diversity in thought and content.

\section{Previous studies:}

A study (Hussein Al-Asraj, 2012) entitled "Activating the role of corporate social responsibility in economic and social development in the Arab countries."

This study aimed at explaining the social role of companies in Arab countries, which was increasing, after a number of companies abandoned their economic roles, as the study indicated that interest in social responsibility has become a basic requirement to reduce poverty, and the study concluded that companies bear their social responsibilities to achieve Many benefits to the local community and companies together, which are to provide healthy goods and products to the community and maintain a clean environment free of pollution and increase the loyalty of employees and the company enjoys credibility.

Saleh Al-Suhaibani's study, 2010 entitled "Social Responsibility and its Role in Private Sector Participation in Development: An Application Case for the Kingdom of Saudi Arabia".

As this study aimed at the role of social responsibility in the private sector's participation in development by examining a set of models and applications on companies in the Kingdom of Saudi Arabia, where the study was taken by Aramco and SABIC, which work together to create a number of classrooms for schools in the regions The remote, Savola company is one of the leading companies in community service in the Kingdom, as it is considered one of the first companies that have been involved in social responsibility and adopted that, and presented a number of programs, including the "After graduation program to where" which aims to rehabilitate and train women and the "hands program" United "to help diabetics.

The study found that the rate of corporate participation in supporting the community did not meet up to $10 \%$ of the dimensions of the globally created concept, and the efforts of the private sector should be directed towards certain societal segments such as children and women, especially widows and divorced women whose number until the date of the study is 360 thousand, as well as adults Age and retirees make up about $3 \%$ of the fabric of society and most of them are low-income or non-existent.

Hussein Al-Asraj, 2014, entitled "Social Responsibility of the Private Sector and its Role in Sustainable Development in the Kingdom of Saudi Arabia"

This research aimed to study the social responsibility of the private sector and its role in the sustainable development of the Kingdom of Saudi Arabia, where the study reached an interest in the topic of social responsibility in the Kingdom of Saudi Arabia and its role in development increased as a result of companies' conviction of this, and there are many reasons that hinder the spread of social responsibility to the private sector in The Kingdom of Saudi Arabia, the most important of which are: - The lack of a culture of social responsibility among most companies, as most of the efforts of these companies are not organized, in addition to the absence of a culture of giving for development as most of the companies efforts are limited to charitable non-development activities related to feeding the poor or providing clothes or Services to them without referring to development projects that fundamentally and sustainably change the standard of living of the poor, lack of experience, knowledge and scientific ability to set standards and criteria for measuring efforts, as there has so far been confusion between charity and social responsibility, the study has made many recommendations for the private sector and governments, the most important of which is the establishment of the state Facilitating procedures 
related to corporate social responsibility, and providing systemic incentives to the private sector in light of Its distinction is in social responsibility.

A study, "Petla Ahmed Al-Hamidi Daaar, 2015) entitled" The Role of the Private Sector in Social Responsibility in the Kingdom of Saudi Arabia

The study aimed to clarify the concept of social responsibility and its pillars. And analyze the reality of social responsibility for private sector companies in the Kingdom of Saudi Arabia. Disclosure of the factors that hinder the role of the Saudi private sector in exercising social responsibility. And get acquainted with the means (mechanisms) of facing (facing) factors that hinder the role of the private sector in exercising social responsibility. Finally, he developed a strategic vision (strategic vision) to enhance the role of the private sector in the field of social responsibility.

And I have come to the most important areas of social responsibility: (social services, health care, educational and training services for young people, contributing to the establishment of infrastructure and public facilities, supporting government activities, and contributing to relief work). Their rights, and finally recommended the provision of infrastructure for the performance of institutions for social responsibility, the development of regulations, the provision of transparency and disclosure, the provision of studies and information in the field of social responsibility, and work to develop a local index linked to the international indicator of social responsibility.

Vimal Srivastava \& Raj Laxmi Srivastava, 2018 "A Review of Public and Private Sector Corporate Social Responsibility (CSR) Practices in India and Present State of Affairs.

This study aimed to demonstrate the role of the social responsibility of the private sector in the development of the local community in India, where the study provides an understanding and clarification about the practices of social responsibility for companies and private and public business institutions in India, and it has concluded that there is a large gap in the goals and spending. Some companies make CSR expenses

According to their desire and will. There is also a lack of experience of companies carrying out corporate social responsibility activities. At the same time,

The lack of professional NGOs dealing with the implementation of corporate social responsibility in India is also evident.

Arlina Nurbaity Lubis, 2017, Business: Theory and Practice, Corporate social responsibility in health sector: a case study in the government hospitals in Medan

This study aimed to demonstrate the social responsibility of companies in the health sector: a case study in government hospitals in the field of Indonesia requires contemporary society that each organization operates with a sense of social responsibility. Many organizations now include CSR activities in their work programs. However in the health sector, the role of corporate social responsibility has not been studied as intensively as in private companies because the services provided by the health sector are already valued as directly serving humanity.

This study aims to address the issue of corporate social responsibility in the field of health care, especially for government hospitals. Emphasizing the special governance arrangements for these complex organizations and assessing whether new models of hospital management will need strong corporate governance mechanisms to achieve a social response, this model was developed by analyzing the impact of corporate social responsibility on hospital reputation, customer loyalty and hospital values. By answering the questionnaires, a total of 200 hospital patients from four government hospitals participated in the study. The proposed model was evaluated using path analysis using AMOS tools.

The study has come to provide empirical evidence that corporate social responsibility generally affects the hospital's reputation, patient loyalty, and hospital value, although there is a direct negative impact of corporate social responsibility on the hospital's value, but the biggest impact of the indirect impact that occurs through the mediating role of reputation and variables Patient loyalty indicates that corporate social responsibility is able to increase the hospital's value from a practical point of view. These results indicate the need to implement corporate social responsibility as a strategic tool in improving hospital value.

\section{Study procedures}

\section{Statistical data processing methods:}

The study used in data processing the statistical methods appropriate to the nature of this study, as follows:

1. Pearson correlation coefficient to measure the validity of the internal consistency of the questionnaire items.

2. Cronbach's Alpha factor for calculating the stability of the resolution.

3. Frequencies and percentages to describe the study sample and determine the percentages of their answers.

4. The arithmetic mean for arranging the study sample answers to the questionnaire terms according to the degree of approval.

\section{Validate the study instrument:}

To ensure the sincerity of the study tool, they were presented to a number of faculty members to take their views about the clarity of their expressions and their suitability of the study questions, and some paragraphs were 
modified based on the opinions and proposals of the arbitrators.

Where the arbitration was regarding the following aspects:

The extent of clarity of the instructions provided to the individuals of the sample.

- The suitability of alternatives to answers to paragraphs

- The suitability of the number of paragraphs for each dimension.

- The clarity of the linguistic wording of the paragraphs and their content being appropriate to the dimension.

\section{Construction Certification:}

To extract the significance of construction sincerity, the parameters of the correlation of the paragraphs with the field to which they belong were extracted, where the paragraphs were analyzed and the correlation coefficient of each of the paragraphs was calculated, as the correlation coefficient here represents a sign of honesty with respect to each paragraph in the form of a correlation coefficient between each paragraph in the field to which it belongs, The following table shows that.

Table (1)

Correlation coefficients between vertebrae and the domain to which they belong

\begin{tabular}{ccccccc}
\hline $\begin{array}{c}\text { Coefficient of } \\
\text { correlation } \\
\text { with the } \\
\text { domain }\end{array}$ & $\begin{array}{c}\text { Paragraph } \\
\text { no. }\end{array}$ & $\begin{array}{c}\text { Coefficient of } \\
\text { correlation } \\
\text { with the } \\
\text { domain }\end{array}$ & $\begin{array}{c}\text { Paragraph } \\
\text { no. }\end{array}$ & $\begin{array}{c}\text { Coefficient of } \\
\text { correlation } \\
\text { with the } \\
\text { domain }\end{array}$ & $\begin{array}{c}\text { Paragraph } \\
\text { no. }\end{array}$ \\
\hline 1 & .522 & 13 & .700 & 25 & .748 & 37 \\
\hline \\
\hline
\end{tabular}

It is clear from Table (1) that the values of the correlation coefficient for each of the statements with the dimension are positive and statistically significant at the level of significance 0.01 and 0.05 , which indicates that all the statements of the questionnaire have a very high degree of sincerity, and confirms the strength of the internal correlation between all statements of the study instrument.

\section{The stability of the study instrument}

The stability coefficient was calculated using the internal consistency method according to the Cronbach alpha equation, and Table No. (2) shows the coherence coefficient according to the Cronbach alpha equation and these values were considered appropriate for the purposes of this study.

Table (2)

The internal consistency coefficient of Cronbach Alpha

\begin{tabular}{clcc} 
No. & \multicolumn{1}{c}{ axis } & Internal consistency & Paragraph no. \\
1 & Social Responsibility & .911 & 9 \\
\hline 2 & The role of the private sector companies & .931 & 21 \\
3 & Constraints facing the private sector & .880 & 15 \\
& Instrument overall & .959 & 45
\end{tabular}

It is clear from Tables No. (2) for high resolution, where it reached (.9590). This indicates that the study tool has a high degree of stability that can be relied upon in the field application of the study.

\section{Statistical standard:}

The Likart five-step scale was adopted to correct the study tools, by giving each of its paragraphs one of the five grades (strongly agree, agree, neutral, disagree, strongly disagree) and they are digitally represented $(5,4,3,2,1)$ on Arrangement.

The study sample:

An intentional sample was chosen to conduct the application of the questionnaire on the official or unofficial 
workers in the civil sector of its various categories, males and females, their level of education, their economic and social level and their ages, where 200 forms were distributed, and 40 questionnaires were excluded because they were not valid for analysis, as the number of the sample reached 160 by $80 \%$

Table No. (3)

Frequencies and percentages according to the study variables

\begin{tabular}{|c|c|c|c|}
\hline Variable & Categories & Repetition & percentage \\
\hline \multirow{3}{*}{ Age Varrable } & Between (20-30) years & 45 & 28.1 \\
\hline & Between $(31-40)$ years & 63 & 39.4 \\
\hline & Between $(41-50)$ years & 52 & 32.5 \\
\hline \multirow[t]{2}{*}{ Gender } & Male & 74 & 46.3 \\
\hline & female & 86 & 53.8 \\
\hline \multirow{3}{*}{$\begin{array}{l}\text { number of family } \\
\text { members }\end{array}$} & Less than 4 people & 74 & 46.3 \\
\hline & From 4-6 individuals & 52 & 32.5 \\
\hline & More than 6 people & 34 & 21.3 \\
\hline \multirow{3}{*}{$\begin{array}{l}\text { University } \\
\text { education level }\end{array}$} & Bachelor & 102 & 57.5 \\
\hline & M.A. & 38 & 33.8 \\
\hline & Ph.D. & 18 & 11.7 \\
\hline \multirow[t]{5}{*}{ Economic level } & Low & 30 & 18.8 \\
\hline & Average & 70 & 43.8 \\
\hline & above average & 45 & 28.1 \\
\hline & high & 15 & 9.4 \\
\hline & Total & 160 & 100.0 \\
\hline
\end{tabular}

It is clear from Table No. (3) that 63 of the study sample represents $39.4 \%$ of the total sample whose ages are less than (31-40) years and they are the most category of the study sample, while (52) of them represent $32.5 \%$ of the total The sample ranges between the ages of the least (41-50) years, compared to 14 of them representing $16.5 \%$ of the total study sample, whose ages range from (20-30) years and they are the lowest category of the study sample as shown in the previous form, as indicated in the previous table The percentage of females was higher than that of the study sample, as it obtained $53.8 \%$, while the percentage of males was $46.3 \%$.

The number of family members ranged from less than 4 members to the highest percentage which was 74 and got a percentage of $46.3 \%$, while the number of family members from 4-6 members was 52 and he got a percentage of 32.5 while more than 6 members was 34 and got a percentage of 21.3 .

University education obtained the highest percentage, which was $57.5 \%$ compared to $11.7 \%$, and the $\mathrm{PhD}$ degree obtained the lowest year which was $1.2 \%$. As for the percentage of income, the highest percentage was average income, as it obtained $43.8 \%$ of the total averages, while the rest was distributed to Above average by $28.1 \%$, low by 18.8 and high by 9.4 .

The main question: What is the role of social responsibility of the private sector in economic development in the Kingdom of Saudi Arabia?

To answer this question, arithmetic averages and standard deviations were extracted for the axes of the role of social responsibility for the private sector and its role in economic development in the Kingdom of Saudi Arabia, and the table below shows that.

Table No. (4)

Arithmetic mean and standard deviations for the axes of the role of social responsibility for the private sector and its role in economic development in the Kingdom of Saudi Arabia are arranged in descending order according to their arithmetic mean.

\begin{tabular}{|c|c|c|c|c|c|}
\hline rank & No. & Paragraph & Mean & deviation & Level \\
\hline 1 & 3 & $\begin{array}{l}\text { Constraints that delay the contribution of the } \\
\text { private sector }\end{array}$ & 3.88 & .510 & High \\
\hline 2 & 2 & The role of the private sector companies & 3.71 & .550 & High \\
\hline 3 & 1 & Social Responsibility & 3.67 & .661 & Moderate \\
\hline & & The instrument as a whole & & .507 & High \\
\hline
\end{tabular}

Table (4) shows that the arithmetic mean ranged between (3.67-3.88), where the axis of the obstacles that delay the contribution of the private sector came in the first place with an average of (3.88), while the axis of the role of the private sector companies came in the second place with an arithmetic mean of (3.71) and with a high degree, while the axis of social responsibility came third, with an average score of (3.67). The mean of the tool as a whole was (3.76).

Accordingly, the role of social responsibility of the private sector in economic development in the Kingdom 
of Saudi Arabia came to a high degree, as the civil sector in the Kingdom of Saudi Arabia plays an important role in development, but there are obstacles that limit the process of the private sector's contribution to the development process.

The first question: What are the positive effects of the participation of the private sector in the economic development of the Kingdom of Saudi Arabia?

To answer this question, mathematical averages and standard deviations were extracted for the paragraphs related to the axis of the role of the private sector companies in the economic development of the Kingdom of Saudi Arabia, and the table below shows that.

Table No. (5)

Arithmetic mean and standard deviations for the axis of the role of the private sector companies in the economic development of the Kingdom of Saudi Arabia are arranged in descending order according to their arithmetic mean.

\begin{tabular}{|c|c|c|c|c|c|}
\hline Rank & No. & $\begin{array}{l}\text { Paragraph } \\
\end{array}$ & Mean & deviation & Level \\
\hline 1 & 19 & The companies contribute to the care of the facilities & 4.46 & .548 & High \\
\hline 2 & 15 & Companies are trying to reduce the burden on central cities & 4.20 & .783 & High \\
\hline 3 & 12 & Companies help women to work hard & 4.09 & .730 & High \\
\hline 4 & 14 & Private sector companies are fighting dropout from education & 3.97 & .772 & High \\
\hline 5 & 13 & Private sector companies contribute to charitable housing & 3.92 & .858 & High \\
\hline 6 & 20 & The companies sponsor the talented & 3.86 & .872 & High \\
\hline 7 & 27 & Private sector companies contribute to religious awareness & 3.83 & .865 & High \\
\hline 8 & 16 & Companies are trying to help the lower classes & 3.82 & .805 & High \\
\hline 8 & 21 & $\begin{array}{l}\text { Companies assist the private sector in establishing social } \\
\text { centers for youth }\end{array}$ & 3.82 & .734 & High \\
\hline 10 & 25 & Private sector companies contribute to the elderly & 3.80 & .889 & High \\
\hline 11 & 23 & Private sector companies contribute to training & 3.71 & .829 & High \\
\hline 12 & 18 & $\begin{array}{l}\text { Companies are trying to reduce the gap between classes } \\
\text { through serious projects }\end{array}$ & 3.67 & .859 & Moderate \\
\hline 13 & 26 & Private sector companies contribute to childhood programs & 3.64 & .980 & Moderate \\
\hline 14 & 22 & Private sector companies contribute to education programs & 3.59 & .927 & Moderate \\
\hline 15 & 29 & Private sector companies contribute to building cemeteries & 3.58 & .781 & Moderate \\
\hline 16 & 17 & Private sector companies contribute to the qualification & 3.48 & .971 & Moderate \\
\hline 17 & 30 & $\begin{array}{l}\text { Private sector companies contribute to helping patients, } \\
\text { insolvent, and marriage seekers }\end{array}$ & 3.43 & .844 & Moderate \\
\hline 18 & 24 & $\begin{array}{l}\text { Private sector companies contribute to caring for people of } \\
\text { determination }\end{array}$ & 3.40 & 1.004 & Moderate \\
\hline 19 & 28 & $\begin{array}{l}\text { Private sector companies contribute to the care and } \\
\text { construction of mosques }\end{array}$ & 3.27 & .791 & Moderate \\
\hline 20 & 11 & Private sector companies contribute to health care & 3.26 & .872 & Moderate \\
\hline \multirow[t]{2}{*}{21} & 10 & $\begin{array}{l}\text { Companies help young people open their own businesses } \\
\text { The role of the private sector companies }\end{array}$ & 3.03 & .934 & Moderate \\
\hline & & & & .550 & High \\
\hline
\end{tabular}

Table (6) shows that the arithmetic averages ranged between (3.03-4.46), as paragraph (19) states that "companies contribute to caring for utilities" came first and with an average of (4.46), while paragraph (10) It reads, "It helps young companies to open their own businesses", with the average score of (3.03). The mean of the axis of the role of the private sector companies as a whole was (3.71).

The second question: What are the effects of spreading a culture of social responsibility for the private sector in the economic development of the Kingdom of Saudi Arabia?

To answer this question, arithmetic averages and standard deviations were extracted for the paragraphs related to the axis of social responsibility for the private sector in the economic development of the Kingdom of Saudi Arabia, and the table below shows that. 
Table No. (6)

Arithmetic mean and standard deviations in the axis of social responsibility of the private sector in the economic development of the Kingdom of Saudi Arabia are arranged in descending order according to their arithmetic mean

\begin{tabular}{|c|c|c|c|c|c|}
\hline Rank & No. & Paragraph & Mean & deviation & Level \\
\hline 1 & 1 & $\begin{array}{l}\text { Social responsibility is concerned with the principle of social } \\
\text { solidarity }\end{array}$ & 3.98 & .677 & High \\
\hline 2 & 8 & $\begin{array}{l}\text { The citizen depends on his abilities through training civil } \\
\text { institutions }\end{array}$ & 3.96 & .931 & High \\
\hline 3 & 5 & Social work has become an organized form & 3.72 & .863 & High \\
\hline 4 & 6 & Social work was limited to the charitable aid of the pilgrims & 3.71 & .850 & High \\
\hline 5 & 4 & We refer social work in the Kingdom to creed & 3.69 & .904 & High \\
\hline 6 & 3 & Social work takes individual forms only & 3.63 & .852 & Moderate \\
\hline 7 & 9 & $\begin{array}{l}\text { Media helps society by spreading a culture of social } \\
\text { responsibility among individuals }\end{array}$ & 3.52 & .911 & Moderate \\
\hline 8 & 7 & $\begin{array}{l}\text { Social responsibility by helping the individual to solve his } \\
\text { problems on his own }\end{array}$ & 3.48 & .868 & Moderate \\
\hline \multirow[t]{2}{*}{9} & 2 & $\begin{array}{l}\text { Social solidarity is one of the most important forms of social } \\
\text { responsibility }\end{array}$ & 3.31 & .892 & Moderate \\
\hline & & Social Responsibility & & .661 & Moderate \\
\hline
\end{tabular}

Table (7) shows that the arithmetic mean ranged between (3.31-3.98), as paragraph (1) states that "social responsibility is concerned with the principle of social solidarity" in the first place with an arithmetic average of (3.98), while paragraph No. (2) Its text, "Social Solidarity is one of the most important forms of social responsibility", at the last rank, with an average of (3.31). The mean of the social responsibility axis as a whole (3.67).

The third question: What are the obstacles facing the private sector in the economic development of the Kingdom of Saudi Arabia?

To answer this question, arithmetic averages and standard deviations were extracted for the paragraphs related to the axis of obstacles facing the private sector in the economic development of the Kingdom of Saudi Arabia, and the table below shows that.

Table No. (8)

Arithmetic mean and standard deviations for the axis of obstacles facing the private sector in the economic development of the Kingdom of Saudi Arabia are arranged in descending order according to their arithmetic mean

\begin{tabular}{|c|c|c|c|c|c|}
\hline Rank & No. & Paragraph & Mean & deviation & Level \\
\hline 9 & 39 & Different thinking style in some areas & 4.42 & .629 & High \\
\hline 15 & 45 & $\begin{array}{l}\text { Scientific steps should be developed to the extent that private } \\
\text { sector institutions contribute to the development of society }\end{array}$ & 4.18 & .760 & High \\
\hline 7 & 37 & $\begin{array}{l}\text { Tribal interests interfere in relations between civil society } \\
\text { organizations }\end{array}$ & 4.14 & .776 & High \\
\hline 5 & 35 & The state is unable to fulfill all the needs of the citizens & 4.06 & .859 & High \\
\hline 12 & 42 & $\begin{array}{l}\text { Intolerance of responsibility for the new generation and a } \\
\text { generation unable to take responsibility for driving or working } \\
\text { in a team }\end{array}$ & 3.99 & .850 & High \\
\hline 6 & 36 & Dealing with civil work according to the tribal social system & 3.95 & .767 & High \\
\hline 10 & 40 & $\begin{array}{l}\text { Economic institutions sometimes biased to political or } \\
\text { religious parties and were affected by their struggles }\end{array}$ & 3.94 & .798 & High \\
\hline 11 & 41 & Imbalance in the pattern of education in society & 3.93 & .645 & High \\
\hline 13 & 43 & $\begin{array}{l}\text { Society does not benefit from new generations, which } \\
\text { negatively affects the national economy of the Kingdom }\end{array}$ & 3.93 & .848 & High \\
\hline 1 & 31 & $\begin{array}{l}\text { Lack of coordination between economic institutions operating } \\
\text { to regulate community work }\end{array}$ & 3.91 & .642 & High \\
\hline 2 & 32 & $\begin{array}{l}\text { Lack of cooperation between economic institutions operating } \\
\text { to regulate community work. }\end{array}$ & 3.69 & 1.052 & High \\
\hline 14 & 44 & $\begin{array}{l}\text { Lack of research and studies centers, field work and systematic } \\
\text { training }\end{array}$ & 3.64 & 1.067 & Moderate \\
\hline 8 & 38 & $\begin{array}{l}\text { The private sector is an essential partner in achieving societal } \\
\text { development in all countries of the world }\end{array}$ & 3.57 & .829 & Moderate \\
\hline 3 & 33 & Lack of specialization in work & 3.50 & .869 & Moderate \\
\hline
\end{tabular}




\begin{tabular}{cclcccc}
\hline Rank & No. & & Paragraph & Mean & deviation & Level \\
4 & $\mathbf{3 4}$ & The limited trained manpower & $\mathbf{3 . 3 4}$ & $\mathbf{. 9 9 1}$ & Moderate \\
& & Constraints facing the private sector as a whole & $\mathbf{3 . 8 8}$ & $\mathbf{. 5 1 0}$ & High \\
\hline
\end{tabular}

Table (8) shows that the arithmetic mean ranged between (4.34-4.42), where paragraph (39), which states "the difference in the thinking pattern in some areas" came first and with an average of (4.42), while paragraph (No. 34) The text states, "The limited number of trained manpower" is in the last rank, with an average of (3.34). The arithmetic mean for the axis of obstacles facing the private sector as a whole was (3.88), as the study reached a set of obstacles that stand in the face of the growing role of social responsibility for the private sector in the development of society, the most important of which was the difference in the thinking pattern in some regions.

\section{Conclusion}

At the end of this research, we find that the private sector is the main element in the establishment of economic activity in the Kingdom in light of the current economic conditions, and because of its challenges in the field of work and initiative and orientation towards creativity and innovation in a way that guarantees it the ability to compete through innovation, creativity and innovation in the field of work This guarantees him a presence in the labor market and has a competitive ability, and a positive impact on the process of economic growth and poverty reduction, as despite the great controversy that economic thought has witnessed about its growing role in economic activity in light of the increasing status and importance of the public sector, it remains present Central and main is not to limit or reduce its influence on the activities of economic activity.

\section{First: the results}

The results of the study showed an increased interest in the social responsibility of the private sector in the Kingdom of Saudi Arabia, and that the private sector plays an important role in development in society, and the results of the study agreed with the study (Al-Asraj, 2014), which reached an increased interest in social responsibility for the private sector in the Kingdom and became a priority In terms of transforming companies into partners in sustainable development, as companies assume their social responsibilities bring many benefits to the local community and companies together, which are to provide healthy goods and products to the community and maintain a clean environment free of pollution and increase employee loyalty and company enjoyment With credibility and create good relationships with shareholders and other stakeholders.

The study also showed that there are positive effects of the participation of the private sector in the economic development of the Kingdom of Saudi Arabia, as the study concluded that companies contribute to caring for facilities and easing burdens on central cities, and companies also help women to work hard, and characterize private sector companies in charitable housing, and in Religious awareness also helps in setting up social centers for youth, and it has a role with children, the elderly and other segments of society. The results of the study agreed with the study of Saleh Al-Suhaibani, 2010, which the study concluded that the efforts of the private sector should be directed towards certain societal segments such as children and women As well as the elderly and retired people, these constitute about $3 \%$ of the fabric of society and most of them are low-income or non-existent.

The study also found that there are many obstacles that limit the spread of social responsibility for the private sector, the most important of which was the difference in the thinking style in some regions, and the limited trained manpower. The results of the study agreed with the study (Al-Asraj, 2014), which concluded that there is no culture of social responsibility Most companies have, and most of the efforts of these companies are not organized, in addition to the absence of a culture of giving for development as most of the companies efforts are limited to nondevelopment charitable work related to feeding the poor or providing clothes or services to them without touching on development projects that radically change the standard of living of the poor And sustainable, lack of experience, knowledge and scientific ability to set standards and criteria for measuring efforts, there is so far confusion between charity and social responsibility.

The study also found that the most prominent social effects of the private sector's contribution to social responsibility include:

Reducing the poverty rate: Through projects that the private sector builds, which supports the poor and contributes to improving their lives, in addition to the Kingdom's strategic plans through the implementation of Vision 2030, all of these factors contribute to reducing the poverty rate.

Low unemployment: Because the projects undertaken by the private sector to develop the private sector need several elements, the most important of which is the human component, which drives the wheel of production. Development of the role of women: and their participation in society, which helps to boost production by involving all segments of society in development.

\section{Recommendations:}

1 - Working to deepen and spread the concept of social responsibility for the private sector in the Kingdom to provide a national project under which voluntary initiatives in the work and the development of civil society in the 
whole Kingdom and not limited to a specific area or provide food to the poor on a particular occasion without the direction to develop individuals, and work in accordance with comprehensive strategies based On studies and research to find an executive mechanism for this partnership with the government sector, and the adoption of the private sector as a partner with the government sector in planning, implementation and evaluation.

2- The inclusion of the new global standards of social responsibility in its four aspects, namely economic development, social aspect, ethical and legal aspects.

3- That the government sector and the private sector establish a multi-purpose fund to provide services and implement social responsibility programs for different sectors, and not only in the economic field, in order to serve all individuals present in the Kingdom.

4- Eliminating the obstacles facing the work of the private sector in its various societies in the Kingdom; By providing the legislative environment that constitutes the legal framework within which the private sector operates, and enhancing confidence in funding sources while creating a mechanism to ensure transparency and accountability.

5- Activating the importance of the media's role in spreading a culture of social responsibility in the Kingdom among private sector institutions. Such as announcing the social efforts exerted to be role models for others, and then everyone in this regard is racing to achieve greater benefit to society, as well as raising public awareness through conferences, seminars and workshops on issues of social responsibility, including encouraging various governmental and private sectors in Egypt to participate Effective.

\section{References}

1. Abdullah bin Ali Al Marwani (2019) Evolution of the methodology of development planning and its institutions, selected international and regional experiences, Arab Planning Institute,

2. Amal bin Nasser (2018) The role of the private sector in achieving local development: a case study of the Omar bin Omar Mills Foundation, the first international scientific forum on: Activating the developmental role of the public sector as a means of promoting the economy outside the hydrocarbon sector, on 27-28 November 2018

3. A ghost's wish / right-wing (2009), the reality of social responsibility in the economic establishment. "Case study of the two institutions, Tahrawi and the cable industry, Biskra, Algeria.

4. Item Eight, Social Responsibility for Private Sector Institutions, The 45th Arab Labor Conference, Cairo, 8-15 April 2018

5. Bodkhadk Kareem / Bodkhadkh Masoud (2011), a theoretical vision on the strategy of developing the private sector in economic activity, University of Muhammad Al-Siddiq Bin Yahya - Jijel, College of Economic Sciences, Commercial Sciences and Management Sciences, a research paper submitted to participate in the activities of the first national forum on: "The role The private sector in raising the competitiveness of the Algerian economy and preparing for the post-oil phase, "on 20 and 21 November 2011

6. Hatem Jamil Al-Harazin / Muhammad Ibrahim Al-Rai (2016) Factors affecting labor productivity and wages in the Palestinian manufacturing industries sector during the period 1994-2012, Jordanian Journal of Applied Sciences, Humanities Series, Volume 18, First Issue.

7. Hussein Abdul-Muttalib Al-Asrah (2014), Social Responsibility of the Private Sector and its Role in the Sustainable Development of the Kingdom of Saudi Arabia, presented the paper to the International Conference entitled: "Corporate Social Responsibility: Challenges and Prospects for Development in the Arab Countries, Saudi Arabia."

8. Khaled Abdel Aziz Hassan Mohamed (2018) Economics of health services and their impact on economic growth in Sudan, Journal of Economic, Administrative and Legal Sciences, No. 15, Volume 2, Arab Journal of Science and Research Publishing.

9. Khawla Talhi (2015), Social Responsibility for the Private Sector in Algeria, MA, Department of Political Science, Faculty of Law and Political Science, Arabi Bin Mahidi University - Umm Al-Bouqi, Algeria. 